\title{
NOTE
}

\section{Vertical movements of a pelagic thresher shark (Alopias pelagicus): insights into the species' physiological limitations and trophic ecology in the Red Sea}

\author{
M. C. Arostegui ${ }^{1, *}$, P. Gaube ${ }^{1}$, M. L. Berumen ${ }^{2}$, A. DiGiulian ${ }^{3}$, B. H. Jones ${ }^{2}$, \\ A. Røstad ${ }^{2}$, C. D. Braun ${ }^{4,5}$ \\ ${ }^{1}$ Air-Sea Interaction and Remote Sensing Department, Applied Physics Laboratory, University of Washington, Seattle, \\ WA 98105, USA \\ ${ }^{2}$ Red Sea Research Center, Biological and Environmental Science and Engineering Division, \\ King Abdullah University of Science and Technology, Thuwal 23955-6900, Saudi Arabia \\ ${ }^{3}$ Saltwater Professional Consulting, Fort Lauderdale, FL 33308, USA \\ ${ }^{4}$ School of Aquatic and Fishery Sciences, University of Washington, Seattle, WA 98105, USA \\ ${ }^{5}$ Present address: Biology Department, Woods Hole Oceanographic Institution, Woods Hole, MA 02543, USA
}

\begin{abstract}
The pelagic thresher shark Alopias pelagicus is an understudied elasmobranch harvested in commercial fisheries of the tropical Indo-Pacific. The species is endangered, overexploited throughout much of its range, and has a decreasing population trend. Relatively little is known about its movement ecology, precluding an informed recovery strategy. Here, we report the first results from an individual pelagic thresher shark outfitted with a pop-up satellite archival transmitting (PSAT) tag to assess its movement with respect to the species' physiology and trophic ecology. A 19 d deployment in the Red Sea revealed that the shark conducted normal diel vertical migration, spending the majority of the day at 200-300 $\mathrm{m}$ in the mesopelagic zone and the majority of the night at 50-150 $\mathrm{m}$ in the epipelagic zone, with the extent of these movements seemingly not constrained by temperature. In contrast, the depth distribution of the shark relative to the vertical distribution of oxygen suggested that it was avoiding hypoxic conditions below $300 \mathrm{~m}$ even though that is where the daytime peak of acoustic backscattering occurs in the Red Sea. Telemetry data also indicated crepuscular and daytime overlap of the shark's vertical habitat use with distinct scattering layers of small mesopelagic fishes and nighttime overlap with nearly all mesopelagic organisms in the Red Sea as these similarly undergo nightly ascents into epipelagic waters. We identify potential depths and diel periods in which pelagic thresher sharks may be most susceptible to fishery interactions, but more expansive research efforts are needed to inform effective management.
\end{abstract}

KEY WORDS: Alopias pelagicus $\cdot \mathrm{nDVM} \cdot$ Endangered $\cdot$ Hypoxia $\cdot$ Mesopelagic $\cdot$ Pelagic thresher shark $\cdot$ PSAT $\cdot$ Red Sea $\cdot$ Scattering layer

\section{INTRODUCTION}

Pelagic thresher sharks Alopias pelagicus occur in open-ocean areas of the tropical Indo-Pacific (Smith et al. 2008) where they are regularly taken in com-

\footnotetext{
${ }^{*}$ Corresponding author: marosteg@uw.edu
}

mercial fisheries (e.g. González-Pestana et al. 2019) and sold in the shark fin trade (Clarke et al. 2006). The pelagic thresher shark is listed as Endangered with a decreasing population trend by the International Union for the Conservation of Nature (Rigby 
et al. 2019) and is a member of one of the most threatened elasmobranch families in the world (Alopiidae; Dulvy et al. 2008). The species is particularly susceptible to overexploitation due to its low population productivity (Liu et al. 2006, Drew et al. 2015). Misidentification of the pelagic thresher shark has precluded accurate assessment of its distribution and behavior (Smith et al. 2008), and it is the least studied of the 3 thresher shark species even though it is the most imperiled.

In particular, there have been no studies of a pelagic thresher shark outfitted with a pop-up satellite archival transmitting (PSAT) tag, and the species' vertical movement patterns remain largely undescribed. This precludes movement ecology comparisons with the common $A$. vulpinus and bigeye $A$. superciliosus thresher sharks (Sepulveda et al. 2005, Smith et al. 2008), or with other pelagic predators that have been the focus of numerous satellite telemetry studies (e.g. Cartamil et al. 2011, Coelho et al. 2015).

The purpose of this study was to provide the first description of the movement ecology of a pelagic thresher shark outfitted with a PSAT tag. Using a high-resolution data set from a juvenile pelagic thresher shark in the Red Sea, in conjunction with concurrent hydrographic and oxygen observations collected by an autonomous ocean glider and lightbased estimates of scattering layer distribution, we identified a normal diel vertical migration pattern and analyzed these movements with respect to the species' physiological constraints and trophic niche.

\section{MATERIALS AND METHODS}

\subsection{Satellite tagging}

One male pelagic thresher shark was tagged with a PSAT tag (miniPAT; Wildlife Computers) $23 \mathrm{~km}$ off the coast of Thuwal, Saudi Arabia, in the eastern Red Sea on 11 January 2020. The shark measured $1.25 \mathrm{~m}$ fork length, which equates to $1.14 \mathrm{~m}$ precaudal length, $2.44 \mathrm{~m}$ total length, and $31.4 \mathrm{~kg}$ total weight based on established regressions for the species (White 2007), and suggests that this individual was a sexually immature juvenile (Tsai et al. 2010). The shark took a baited hook at $\sim 300 \mathrm{~m}$ depth during the daytime and, after a 28 min fight on electric rod-andreel, was tagged alongside the vessel. The tag was applied into the musculature near the base of the dorsal fin using a titanium dart as an anchor. The fishing line was cut at the corner of the mouth and the hook left in the posterior of the shark's buccal cavity at the time of release because the hook could not safely be removed. The tag was programmed for a 3 mo deployment and logged pressure (depth), temperature, and light level every $5 \mathrm{~s}$ to onboard memory. Data were summarized into $75 \mathrm{~s}$ resolution time series that were transmitted via Argos satellites after tag release.

\subsection{Geolocation methods}

The most probable track of the pelagic thresher shark was constructed using the HMMOCE package (Braun et al. 2018). This approach combines tag-based measurements of light levels, sea surface temperature, and depth-temperature profiles with bathymetry and oceanographic observations and model outputs to construct likelihoods of the tagged individual's movements. Likelihoods from each of the aforementioned inputs are convolved (i.e. combined via integral transform) in a gridded hidden Markov model that computes an output of posterior probability distributions to estimate the most likely state (position) of the animal at each time point (see the Supplement at www. int-res.com/articles/suppl/n043p387_supp.pdf).

\subsection{Autonomous ocean glider}

Oceanographic data (potential temperature and dissolved oxygen) were collected concurrent with and spatially proximate to the most probable track of the pelagic thresher shark by the King Abdullah University of Science and Technology (KAUST) sustained glider line at $22.2^{\circ} \mathrm{N}$ (see the Supplement). The glider transect extends from a point $\sim 20 \mathrm{~km}$ west of the coast (beyond the coastal reefs) to approximately $100 \mathrm{~km}$ offshore, within Saudi Arabia's exclusive economic zone (see Fig. 1).

\subsection{Time-at-depth, -temperature, and -oxygen}

Time-at-depth (TAD), time-at-temperature (TAT), and time-at-oxygen (TAO, based on concurrent oxygen observations collected by the glider) were calculated with the proportion of time spent in each depth, temperature, and dissolved oxygen bin. The 75 s resolution time series data were classified into daytime (sunrise to sunset) and nighttime (sunset to sunrise) categories to assess diel changes in depth distribution. Proportions were calculated for each $24 \mathrm{~h}$ period and then averaged to determine the mean daily and nightly TAD, TAT, and TAO profiles. TAD and TAT 
were calculated using tag data; TAO was estimated using the most proximate glider data (see the Supplement). These calculations excluded data from the days in which the shark exhibited irregular, postrelease behavior due to tagging effects (11-13 January), as well as from the day preceding and the day of its inferred mortality (29-30 January).

\subsection{Occupation of hypoxic waters in the mesopelagic zone}

The inclusion of in situ contemporaneous dissolved oxygen data from an autonomous ocean glider is rare in telemetry studies; most do not include oxygen data and those that do typically use climatological model outputs or ship-based CTD-O ${ }_{2}$ profiles from a limited number of sites (Coffey \& Holland 2015). With the glider-recorded dissolved oxygen measurements aligned to the most probable track, we compared the shark's occupation of low oxygen conditions relative to their prevalence in the water column. We used the 3 categories of hypoxia defined by Hofmann et al.
(2011) (upper thresholds in $\mathrm{ml} \mathrm{O}_{2} \mathrm{l}^{-1}$ : A: mild hypoxia: 2.4 ; B: hypoxia: 1.4 ; C: severe hypoxia: 0.5$)$, as well as a fourth category for non-hypoxic waters. We analyzed data exclusively from the mesopelagic zone (>200 m depth), which is where low oxygen conditions occur in the Red Sea.

\subsection{Light comfort zones of acoustic scattering layers}

The Red Sea exhibits 3 mesopelagic acoustic scattering layers that occupy distinct light comfort zones (Røstad et al. 2016), and thus adjust their depth distribution in response to changes in downwelling irradiance (Kaartvedt et al. 2017). To estimate the depth distribution of these scattering layers during the study period, we used above-surface light measurements in concert with an empirically derived light attenuation equation to predict the depths of the isolumes that define the light comfort zone boundaries of each layer (see the Supplement).

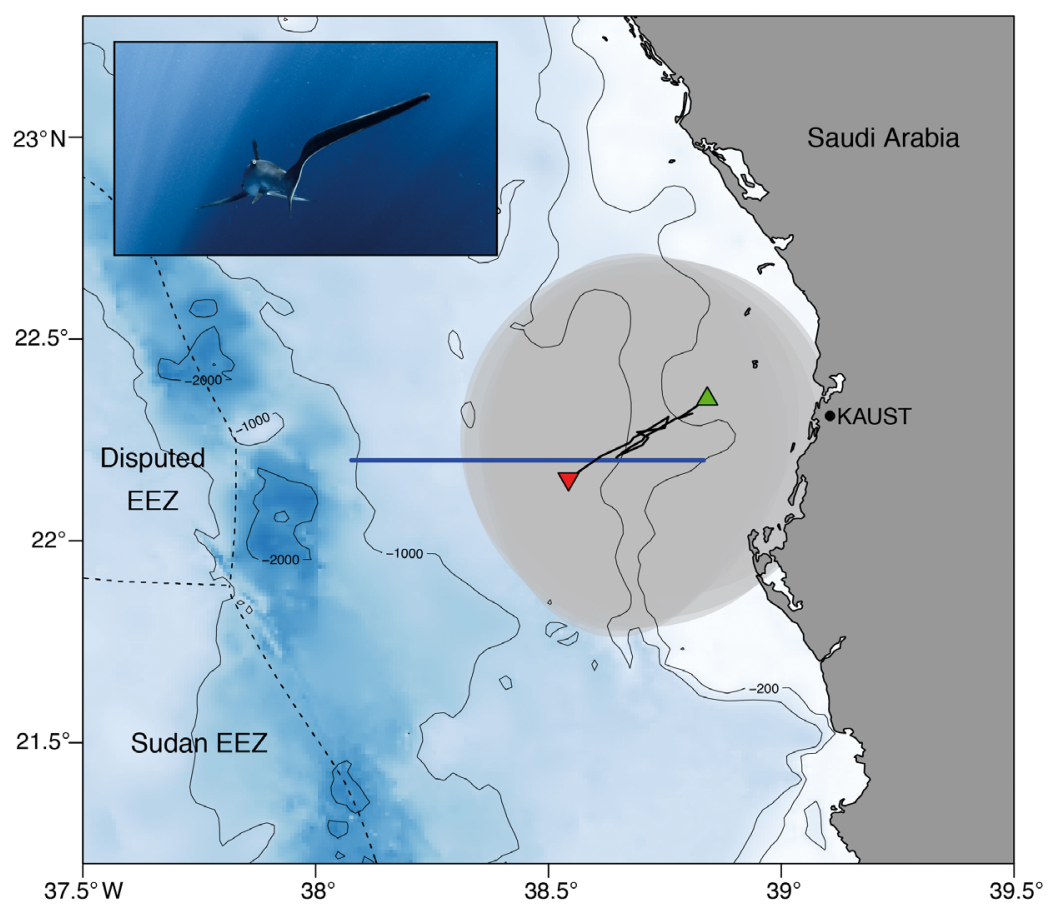

Fig. 1. Movements of the pelagic thresher shark (inset) outfitted with a pop-up satellite archival transmitting tag in the Red Sea. Black solid line: movement track; green and red triangles: tagging and end locations, respectively; grey ellipses: $95 \%$ likelihood contour for each position estimate at $12 \mathrm{~h}$ intervals; blue horizontal line: survey path of a concurrently deployed autonomous ocean glider; dashed black lines: exclusive economic zone (EEZ) boundaries; blue shading and contours: bathymetry $(\mathrm{m})$. Inset photo: Morgan Bennett-Smith

\section{RESULTS}

The most likely track estimate identified movement towards the southwest in waters $<1000 \mathrm{~m}$ bottom depth (Fig. 1, see the Supplement). The depth-time series data from the shark suggested a period of irregular post-release behavior during the first $1.5 \mathrm{~d}$ after release, followed by a regular pattern of normal diel vertical migration for $15 \mathrm{~d}$ (Fig. 2). Eighteen days into the deployment, the shark exhibited erratic but vertically less extensive movements prior to an inferred mortality event the following day in which the fish approached the surface prior to sinking to $649 \mathrm{~m}$ depth, where the tag remained for $17 \mathrm{~h}$ before initiating a mortality related pop-off and ascending to the surface (Fig. 2).

During the $15 \mathrm{~d}$ period of normal diel vertical migration behavior, the shark vertically migrated from mesopelagic to epipelagic waters at dusk and did the reverse at dawn (Fig. 2). Migrations among these 2 zones were largely direct and uninterrupted, whereas movements within these zones consisted of repeated descents and ascents over a comparatively limited depth range (individual displacements were typically $<40 \mathrm{~m}$; Fig. 2). The pelagic thresher shark occupied significantly deeper 

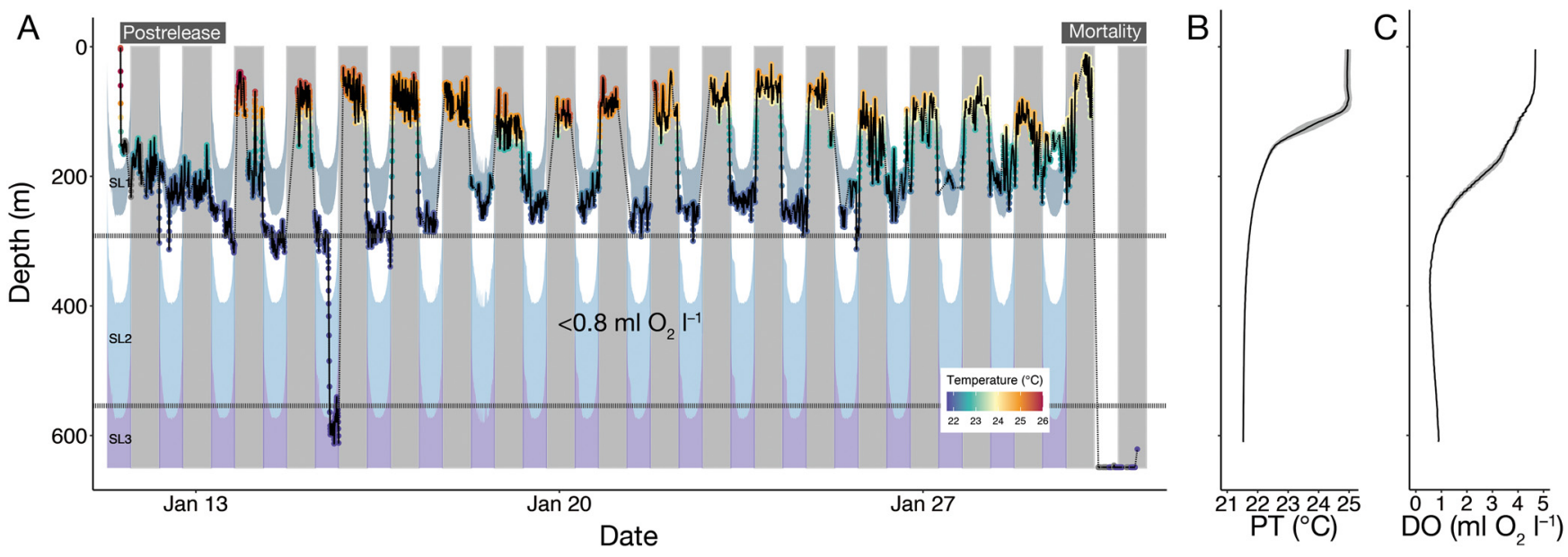

Fig. 2. (A) Depth-temperature time series (75 s interval) of the pelagic thresher shark. Color points: in situ temperature recorded by the pop-up satellite archival transmitting tag (or estimated from interpolation); grey points: depths records without associated temperature data; solid black lines: times with transmitted vertical movement data; dashed black lines connecting solid black lines: times with missing depth data; white and grey backgrounds: day and night, respectively. Periods of irregular post-release behavior and inferred mortality are denoted at the top. Dark grey, dashed, horizontal lines: depth range of waters with $<0.8 \mathrm{ml} \mathrm{O}_{2} \mathrm{l}^{-1}$; dark blue (SL1), light blue (SL2), and purple (SL3) shading indicate estimated daytime depth distributions of the 3 mesopelagic scattering layers. (B,C) Concurrent glider measurements of (B) potential temperature (PT) and

(C) dissolved oxygen (DO) showing mean ( $\pm 95 \%$ CI) across the eastern half of the 2 transects in January 2020
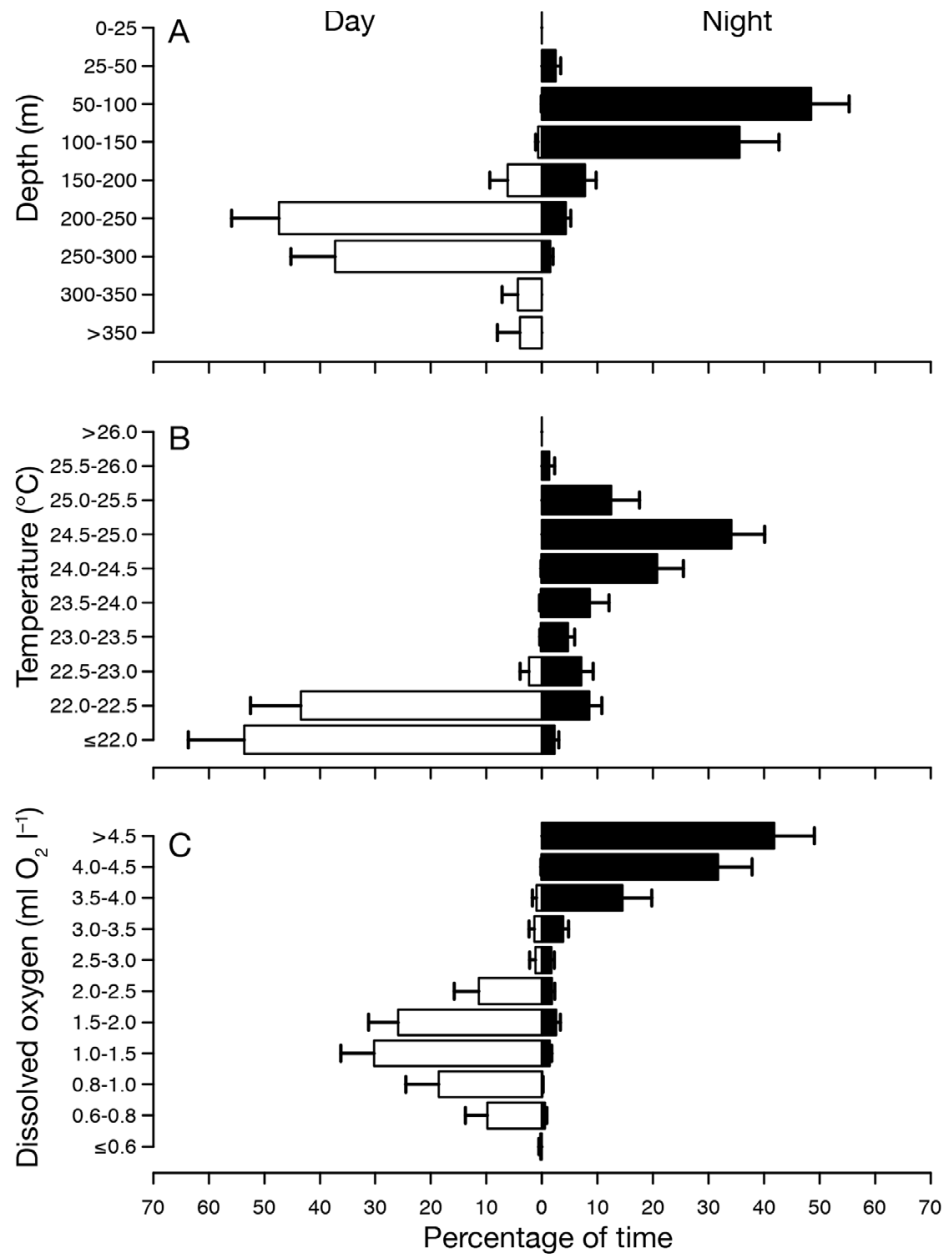

waters during the day (mean: $257 \mathrm{~m}$ ) than at night (mean: $106 \mathrm{~m}$ ) (Welch's 2-sample $t$-test: $t=$ $139.2, \mathrm{p}<0.0001)$. On average, the shark spent $85 \%$ of the day at $200-300 \mathrm{~m}$ and $84 \%$ of the night at 50-150 m (Fig. 3A). While largely restricting its overall depth distribution to 50$300 \mathrm{~m}$, the shark was recorded conducting a single descent to $632 \mathrm{~m}$ which represented the maximum depth observed during this deployment.

Correspondingly, the mean temperature experienced by the pelagic thresher shark during the daytime $\left(22.1^{\circ} \mathrm{C}\right)$ was significantly colder than during the nighttime $\left(24.2^{\circ} \mathrm{C}\right)(t=-187.6$, $\mathrm{p}<0.0001$ ). On average, the shark spent $97 \%$ of the day in waters $\leq 22.5^{\circ} \mathrm{C}$ and $89 \%$ of the night in waters $>22.5^{\circ} \mathrm{C}$ (Fig. 3B). Maximum changes in temperature experienced by the shark in each $24 \mathrm{~h}$ period were $\leq 4.2^{\circ} \mathrm{C}$ (mean \pm SE: $3.4 \pm$ $0.2^{\circ} \mathrm{C}$ ). The pelagic thresher shark occupied an overall temperature range of $21.6-26.1^{\circ} \mathrm{C}$ during the deployment.

Fig. 3. Mean $( \pm 1 \mathrm{SE})(\mathrm{A})$ time-at-depth, (B) time-attemperature, and (C) time-at-(glider-recorded)-oxygen by diel period. White: daytime; black: nighttime. Depth and temperature data come from the pop-up satellite archival transmitting tag; oxygen data were obtained by matching the pelagic thresher shark's horizontal track and vertical movements to corresponding measurements from the autonomous ocean glider 
Parallel to the aforementioned diel patterns, the mean glider-recorded dissolved oxygen potentially experienced by the pelagic thresher shark during the daytime $\left(1.4 \mathrm{ml} \mathrm{O}_{2} \mathrm{l}^{-1}\right)$ was significantly lower than during the nighttime $\left(4.1 \mathrm{ml} \mathrm{O}_{2} \mathrm{l}^{-1}\right)(t=-219.5, \mathrm{p}<$ $0.0001)$. The shark was estimated, on average, to have spent $86 \%$ of the day in waters with $0.8-2.5 \mathrm{ml}$ $\mathrm{O}_{2} \mathrm{l}^{-1}$ and $94 \%$ of the night in waters with $>2.5 \mathrm{ml} \mathrm{O}_{2}$ $\mathrm{l}^{-1}$ (Fig. 3C). In the mesopelagic zone, the proportion of time the pelagic thresher shark occupied nonhypoxic, mildly hypoxic, hypoxic, and severely hypoxic waters was significantly different from their relative prevalence (Pearson's $\chi^{2}$ test: $\chi^{2}=1803.6, \mathrm{p}<$ 0.0001). In particular, the shark appeared to occupy mildly hypoxic conditions more frequently (44.6\% occupation vs. 9.1\% prevalence) and hypoxic conditions less often $(54.9 \%$ occupation vs. $86.5 \%$ prevalence), with the greatest disparity seemingly occurring in waters with $\leq 0.8$ but $>0.5 \mathrm{ml} \mathrm{O}_{2} \mathrm{l}^{-1}(11.0 \%$ occupation vs. $57.6 \%$ prevalence) (Fig. 4). Negligible occupation of non-hypoxic and severely hypoxic conditions in the mesopelagic zone paralleled their minimal prevalence.

Based on ambient light levels, the 3 mesopelagic scattering layers were estimated to descend and progressively widen from dawn to noon, achieve maximum and widest depth distributions at noon, and ascend and progressively narrow from noon to dusk. The estimated depth distributions (at local noon) of the 3 mesopelagic scattering layers were 200-270, 400-580, and 580-800 m (assuming no bathymetric constraint) (Fig. 2A). During the daytime, the shark primarily occupied depths close to or within the esti-

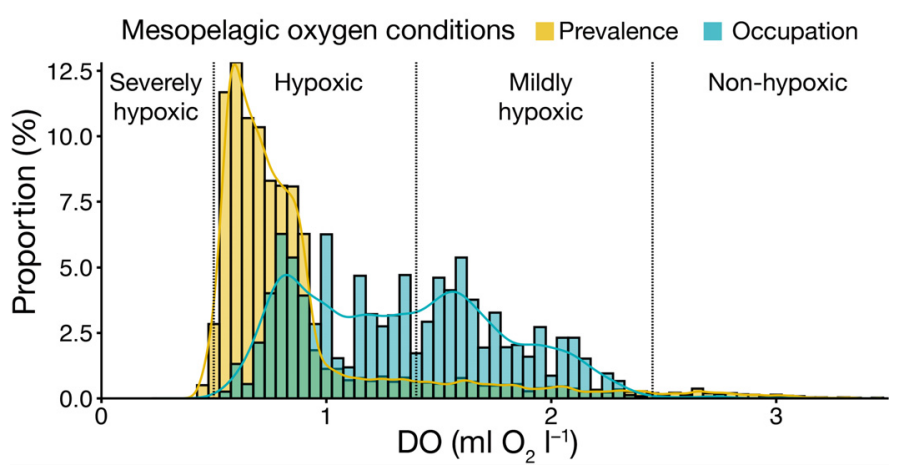

Fig. 4. Occupation of low oxygen conditions by the pelagic thresher shark relative to prevalence of those conditions in the mesopelagic zone, as recorded by the autonomous ocean glider across the eastern half of the 2 transects in January 2020. Data is restricted to depths from $200 \mathrm{~m}$ (the upper limit of the mesopelagic zone) to $610 \mathrm{~m}$ (the lower limit of glider measurements), and is summarized into bins of 0.05 width. Solid colored lines: probability density functions; dashed vertical lines: thresholds of hypoxia categories defined by Hofmann et al. (2011) mated distribution of scattering layer 1 (Fig. 2A). In contrast, daytime overlap with the estimated distribution of scattering layers 2 and 3 was almost exclusively around crepuscular periods; the shark appeared to occasionally track these layers downwards in the mornings until encountering more hypoxic waters and sometimes descended around dusk to intercept them during their upwards migration (Fig. 2A,C). Furthermore, the shark's only potential midday overlap with scattering layers 2 and 3 occurred outside of the most hypoxic waters at the bottom of layer 2's and top of layer 3's estimated distributions around $600 \mathrm{~m}$ (Fig. 2A,C).

\section{DISCUSSION}

The observed behavior of the pelagic thresher shark switching from a deeper daytime to shallower nighttime distribution (Fig. 2) is consistent with the normal diel vertical migration behavior observed in the common thresher shark (e.g. Cartamil et al. 2011) and bigeye thresher shark (e.g. Weng \& Block 2004). Among juveniles of these 3 congeners, the daytime distribution of the pelagic thresher shark we tagged (predominantly $>200 \mathrm{~m}$; Fig. 3A) was more similar to that of the bigeye thresher shark (which almost exclusively occupies mesopelagic waters during the day; Coelho et al. 2015) than to that of the common thresher shark (which remains in epipelagic waters; Cartamil et al. 2011, 2016). While this intrageneric comparison is confounded by the disparate oceanographic conditions of the underlying studies (which were conducted in the Red Sea, tropical eastern North Atlantic, and subtropical eastern North Pacific, respectively), the patterns align with the physiological differences among the alopiid species. The pelagic and bigeye thresher sharks both likely exhibit cranial endothermy because they each contain orbital retia mirabilia (vascular structures akin to a counter-current heat exchanger; Weng \& Block 2004), whereas the common thresher shark is the only alopiid that exhibits endothermy within centrally positioned red myotomal muscle (Sepulveda et al. 2005, Patterson et al. 2011). Thus, the potential warming of the eyes and brain of pelagic and bigeye thresher sharks may expand their depth niche further into the mesopelagic zone (Weng \& Block 2004), while the centralized warming of the common thresher shark may expand its regional niche into cold-temperate latitudes (Patterson et al. 2011).

The extent of normal diel vertical migration by the individual in this study was seemingly not constrained by temperature in the Red Sea (Fig. 2A,B). 
Daily changes in temperature experienced by the pelagic thresher shark from the surface to its deepest descent were always $\leq 4.2^{\circ} \mathrm{C}$, consistent with the atypical oceanographic conditions of the Red Sea in which the water is at or near the notably warm minimum temperature of $21.6^{\circ} \mathrm{C}$ from $\sim 200 \mathrm{~m}$ down to the deepest point of the basin (Yasuhara \& Danovaro 2016, Zarokanellos et al. 2017). This relatively small vertical gradient in temperature during normal diel vertical migration of the pelagic thresher shark strongly contrasts with those exceeding 10, 15, or even $20^{\circ} \mathrm{C}$ experienced by different pelagic shark and fish species in other ocean basins (e.g. bigeye thresher shark, Coelho et al. 2015; black marlin Istiompax indica, Williams et al. 2017; swordfish Xiphias gladius, Braun et al. 2019). Furthermore, unlike some pelagic fish species that undergo repeated movements through the mixed layer during the daytime, presumably to thermoregulate (e.g. Cartamil \& Lowe 2004), the pelagic thresher shark spent almost the entirety of the daytime below $200 \mathrm{~m}$ in or near the minimum available temperature (Fig. 3A,B). The evidence from the individual in this study suggests that the vertical distribution of similarly sized and larger pelagic thresher sharks may not be thermally limited within the Red Sea, as the juvenile we tagged presumably has less thermal inertia than (sub)adults of greater body size (sensu Nakamura et al. 2020).

The pelagic thresher shark exhibited increased mesopelagic occupation of mildly hypoxic waters relative to their prevalence but rarely occupied hypoxic waters with $<0.8 \mathrm{ml} \mathrm{O}_{2} \mathrm{l}^{-1}$ (Fig. 4), even though they were pervasive in the area as part of an oxygen minimum zone that is present throughout the Red Sea (Klevjer et al. 2012). Furthermore, the pelagic thresher shark spent minimal time from $\sim 300-550 \mathrm{~m}$ (where waters with $<0.8 \mathrm{ml} \mathrm{O}_{2} \mathrm{l}^{-1}$ were recorded by the glider; Fig. 2A,C) even though that depth range largely encompasses the peak acoustic backscattering of mesopelagic organisms during the day (Klevjer et al. 2012, Dypvik \& Kaartvedt 2013). This is highlighted by the shark's single extended descent beyond $300 \mathrm{~m}$ in which it rapidly traversed the oxygen minimum zone and spent $\sim 6 \mathrm{~h}$ at around $600 \mathrm{~m}$ where oxygen concentrations increased to $>0.8 \mathrm{ml} \mathrm{O}_{2} \mathrm{l}^{-1}$ (Fig. 2A,C). Respiratory adaptations may expand the species' tolerance of low oxygen conditions (Wootton et al. 2015), but this pelagic thresher shark's apparent avoidance of more hypoxic waters is paralleled by studies documenting hypoxia-induced stress in tropical tunas (e.g. Bushnell et al. 1990) and vertical habitat compression of istiophorid billfishes in regions with shallow, strong oxyclines (e.g. Prince \& Goodyear 2006).
While seemingly curtailed by more hypoxic conditions, the deep movements of the tagged pelagic thresher shark are in accordance with the species' trophic niche similarity to other predators foraging on small mesopelagic fishes, such as swordfish and bigeye tuna Thunnus obesus (Moteki et al. 2001, Varghese et al. 2014). The Red Sea exhibits 3 stratified mesopelagic scattering layers during the daytime; scattering layer 1 -the shallowest layer-occurs above the oxygen minimum zone and is separated by an acoustic void from the deeper scattering layers 2 and 3, which are adjacent to each other and occur within and below the oxygen minimum zone, respectively (Klevjer et al. 2012, Dypvik \& Kaartvedt 2013). The pelagic thresher shark tagged in this study primarily remained above the oxygen minimum zone during the daytime where it overlapped with scattering layer 1 (Fig. 2A), which largely contains sternoptychid fishes (Dalpadado \& Gjosaeter 1987, Klevjer et al. 2012). The shark possibly interacted with scattering layers 2 and 3, however, by tracking them downward during their dawn descent or descending to intercept them during their dusk ascent, with the vertical extent of these crepuscular interactions mostly restricted to waters above or near the upper boundary of the oxygen minimum zone. Although rare, daytime forays below the oxygen minimum zone may enable the shark to further overlap with these deeper scattering layers containing phosichthyid and myctophid fishes (Dalpadado \& Gjosaeter 1987, Dypvik \& Kaartvedt 2013) but possibly also demersal fishes when in neritic waters (Rosas-Luis et al. 2017).

Larger squid have also been documented in numerous studies as being an important part, or even the majority, of the diet of pelagic thresher sharks (Rosas-Luis et al. 2017, González-Pestana et al. 2019). In the Red Sea, patches of what are thought to be squid Sthenoteuthis spp. occur primarily at 1100$1300 \mathrm{~m}$ during the day (Kaartvedt et al. 2020) — far outside of the observed depth range of the pelagic thresher shark in this study. Trophic interactions between this pelagic thresher shark and squid may have occurred at night when both underwent normal diel vertical migration into epipelagic waters (Kaartvedt et al. 2020, this study) but it is unclear what prey species the shark targeted during this time because nearly all mesopelagic biomass in the Red Sea ascends to $<200$ m depth at night (Klevjer et al. 2012).

Our findings, based on an opportunistic, short deployment of a single individual, provide one of the first high-resolution views into the ecology of the pelagic thresher shark; however, more data is needed to determine if the behaviors we documented are 
representative of the species, particularly in different oceanic regimes and across other size classes. We have identified potential depths and diel periods in which pelagic thresher sharks may be most susceptible to fishery interactions (deep in the day and shallow at night), but more expansive tagging efforts are needed to confirm this pattern and inform regulations aimed at reducing interactions with this endangered species. Such research is especially important in the Arabian Sea and adjacent waters, where thresher sharks constitute some of the most common by-catch species encountered by commercial fishing fleets (Jabado et al. 2018), and is further highlighted by the high mortality rate of these sharks captured in such fisheries (e.g. Coelho et al. 2012). Effective fisheries management in the region could further be informed by long-term telemetry deployments (e.g. Oliver et al. 2019) that elucidate the species' migration patterns and aggregation sites, as well as by genetic sampling (e.g. Cardeñosa et al. 2014) that determines population structure within the Indian Ocean and across the Indo-Pacific divide.

Acknowledgements. We thank Colleen Campbell, Royale Hardenstine, Alexander Kattan, Morgan Bennett-Smith, and Christine Nelson for logistical support, Pierre Sanchez, Hussain Zuhair Aqad, Ender Sertel, Amr El-Sayed Jalal ElDin, and the mechanics team of the Coastline LLC vessel 'Bluewater' for fieldwork assistance, and Dag Aksnes for guidance on irradiance calculations. Glider operations were supported by KAUST's Coastal and Marine Resources Core Lab with specific support from Samer Mahmoud, Thomas Hoover, and Andres Espinoza. Mustapha Ouhssain oversaw the glider operations from the Integrated Ocean Process group. This research was funded by a KAUST Center Partnership Fund award (4107.3 to the Red Sea Research Center) and KAUST baseline funding (B.H.J. and M.L.B.). M.C.A. and P.G. acknowledge support from NOAA project NA15OAR4320063. This study was conducted under a protocol approved by the University of Washington's Institutional Animal Care and Use Committee.

\section{LITERATURE CITED}

Braun CD, Galuardi B, Thorrold SR (2018) HMMocE: an R package for improved geolocation of archival-tagged fishes using a hidden Markov method. Methods Ecol Evol 9:1212-1220

Braun CD, Gaube P, Afonso P, Fontes J, Skomal GB, Thorrold SR (2019) Assimilating electronic tagging, oceanographic modelling, and fisheries data to estimate movements and connectivity of swordfish in the North Atlantic. ICES J Mar Sci 76:2305-2317

Bushnell PG, Brill RW, Bourke RE (1990) Cardiorespiratory responses of skipjack tuna (Katsuwonus pelamis), yellowfin tuna (Thunnus albacares), and bigeye tuna (Thunnus obesus) to acute reductions of ambient oxygen. Can J Zool 68:1857-1865
Cardeñosa D, Hyde J, Caballero S (2014) Genetic diversity and population structure of the pelagic thresher shark (Alopias pelagicus) in the Pacific Ocean: evidence for two evolutionarily significant units. PLOS ONE 9:e110193

Cartamil DP, Lowe CG (2004) Diel movement patterns of ocean sunfish Mola mola off southern California. Mar Ecol Prog Ser 266:245-253

Cartamil DP, Sepulveda CA, Wegner NC, Aalbers SA, Baquero A, Graham JB (2011) Archival tagging of subadult and adult common thresher sharks (Alopias vulpinus) off the coast of southern California. Mar Biol 158:935-944

Cartamil D, Wraith J, Wegner NC, Kacev D and others (2016) Movements and distribution of juvenile common thresher sharks Alopias vulpinus in Pacific coast waters of the USA and Mexico. Mar Ecol Prog Ser 548:153-163

* Clarke SC, McAllister MK, Milner-Gulland EJ, Kirkwood GP and others (2006) Global estimates of shark catches using trade records from commercial markets. Ecol Lett 9:1115-1126

Coelho R, Fernandez-Carvalho J, Lino PG, Santos MN (2012) An overview of the hooking mortality of elasmobranchs caught in a swordfish pelagic longline fishery in the Atlantic Ocean. Aquat Living Resour 25:311-319

* Coelho R, Fernandez-Carvalho J, Santos MN (2015) Habitat use and diel vertical migration of bigeye thresher shark: overlap with pelagic longline fishing gear. Mar Environ Res 112:91-99

Coffey DM, Holland KN (2015) First autonomous recording of in situ dissolved oxygen from free-ranging fish. Anim Biotelem 3:47

*Dalpadado P, Gjosaeter J (1987) Observations of mesopelagic fish from the Red Sea. Mar Biol 96:173-183

* Drew M, White WT, Dharmadi, Harry AV, Huveneers C (2015) Age, growth and maturity of the pelagic thresher Alopias pelagicus and the scalloped hammerhead Sphyrna lewini. J Fish Biol 86:333-354

*Dulvy NK, Baum JK, Clarke S, Compagno LJV and others (2008) You can swim but you can't hide: the global status and conservation of oceanic pelagic sharks and rays. Aquat Conserv 18:459-482

* Dypvik E, Kaartvedt S (2013) Vertical migration and diel feeding periodicity of the skinnycheek lanternfish (Benthosema pterotum) in the Red Sea. Deep Sea Res I 72:9-16

* González-Pestana A, Acuña-Perales N, Córdova F, Coasaca J, Alfaro E, Alfaro-Shigueto J, Mangel JC (2019) Feeding habits of thresher sharks Alopias sp. in northern Peru: predators of Humboldt squid (Dosidicus gigas). J Mar Biol Assoc UK 99:695-702

* Hofmann AF, Peltzer ET, Walz PM, Brewer PG (2011) Hypoxia by degrees: establishing definitions for a changing ocean. Deep Sea Res I 58:1212-1226

Jabado RW, Kyne PM, Pollom RA, Ebert DA and others (2018) Troubled waters: threats and extinction risk of the sharks, rays and chimaeras of the Arabian Sea and adjacent waters. Fish Fish 19:1043-1062

Kaartvedt S, Røstad A, Aksnes DL (2017) Changing weather causes behavioral responses in the lower mesopelagic. Mar Ecol Prog Ser 574:259-263

* Kaartvedt S, Røstad A, Christiansen S, Klevjer TA (2020) Diel vertical migration and individual behavior of nekton beyond the ocean's twilight zone. Deep Sea Res I 160: 103280

K Klevjer TA, Torres DJ, Kaartvedt S (2012) Distribution and diel vertical movements of mesopelagic scattering layers 
in the Red Sea. Mar Biol 159:1833-1841

Liu KM, Chang YT, Ni IH, Jin CB (2006) Spawning per recruit analysis of the pelagic thresher shark, Alopias pelagicus, in the eastern Taiwan waters. Fish Res 82:56-64

Moteki M, Arai M, Tsuchiya K, Okamoto H (2001) Composition of piscine prey in the diet of large pelagic fish in the eastern tropical Pacific Ocean. Fish Sci 67:1063-1074

Nakamura I, Matsumoto R, Sato K (2020) Body temperature stability in the whale shark, the world's largest fish. J Exp Biol 223:jeb210286

Oliver SP, Grothues TM, Williams AL, Cerna V and others (2019) Risk and resilience: high stakes for sharks making transjurisdictional movements to use a conservation area. Biol Conserv 230:58-66

Patterson JC, Sepulveda CA, Bernal D (2011) The vascular morphology and in vivo muscle temperatures of thresher sharks (Alopiidae). J Morphol 272:1353-1364

Prince ED, Goodyear CP (2006) Hypoxia-based habitat compression of tropical pelagic fishes. Fish Oceanogr 15: 451-464

Rigby CL, Barreto R, Carlson J, Fernando D and others (2019) Alopias pelagicus. The IUCN Red List of Threatened Species 2019:e.T161597A68607857. https://dx.doi. org/10.2305/IUCN.UK.2019-3.RLTS.T161597A68607857. en (accessed May 2020)

Rosas-Luis R, Navarro J, Loor-Andrade P, Forero MG (2017) Feeding ecology and trophic relationships of pelagic sharks and billfishes coexisting in the central eastern Pacific Ocean. Mar Ecol Prog Ser 573:191-201

Røstad A, Kaartvedt S, Aksnes DL (2016) Light comfort zones of mesopelagic acoustic scattering layers in two contrasting optical environments. Deep Sea Res I 113:1-6

Sepulveda CA, Wegner NC, Bernal D, Graham JB (2005) The red muscle morphology of the thresher sharks (family Alopiidae). J Exp Biol 208:4255-4261

Editorial responsibility: Austin Gallagher, Herndon, Virginia, USA
Smith SE, Rasmussen RC, Ramon DA, Cailliet GM (2008) The biology and ecology of thresher sharks (Alopiidae). In: Camhi MD, Pikitch EK, Babcock EA (eds) Sharks of the open ocean: biology, fisheries and conservation. Blackwell Science, Oxford, p 60-68

Tsai WP, Liu KM, Joung SJ (2010) Demographic analysis of the pelagic thresher shark, Alopias pelagicus, in the north-western Pacific using a stochastic stage-based model. Mar Freshw Res 61:1056-1066

*Varghese SP, Somvanshi VS, Dalvi RS (2014) Diet composition, feeding niche partitioning and trophic organisation of large pelagic predatory fishes in the eastern Arabian Sea. Hydrobiologia 736:99-114

Weng KC, Block BA (2004) Diel vertical migration of the bigeye thresher shark (Alopias superciliosus), a species possessing orbital retia mirabilia. Fish Bull 102:221-229

*White TW (2007) Biological observations on lamnoid sharks (Lamniformes) caught by fisheries in eastern Indonesia. J Mar Biol Assoc UK 87:781-788

Williams SM, Holmes BJ, Tracey SR, Pepperell JG, Domeier ML, Bennett MB (2017) Environmental influences and ontogenetic differences in vertical habitat use of black marlin Istiompax indica in the southwestern Pacific. R Soc Open Sci 4:170694

* Wootton TP, Sepulveda CA, Wegner NC (2015) Gill morphometrics of the thresher sharks (Genus Alopias): correlation of gill dimensions with aerobic demand and environmental oxygen. J Morphol 276:589-600

* Yasuhara M, Danovaro R (2016) Temperature impacts on deep-sea biodiversity. Biol Rev Camb Philos Soc 91: $275-287$

Z Zarokanellos ND, Papadopoulos VP, Sofianos SS, Jones BH (2017) Physical and biological characteristics of the winter-summer transition in the central Red Sea. J Geophys Res C Oceans 122:6355-6370

Submitted: July 14, 2020; Accepted: October 6, 2020 Proofs received from author(s): November 25, 2020 